\title{
PENENTUAN KESETIMBANGAN, TERMODINAMIKA DAN KINETIKA ADSORPSI ARANG AKTIF TEMPURUNG KELAPA SAWIT PADA ZAT WARNA REACTIVE RED DAN DIRECT BLUE
}

\author{
Rensy Aula Sari*1 ${ }^{1}$ M. Lutfi Firdaus ${ }^{2}$, Rina Elvia ${ }^{3}$ \\ ${ }^{1,2,3}$ Program Studi Pendidikan Kimia Jurusan Matematika dan Ilmu Pengetahuan FKIP UNIB \\ *1 e-mail : rensy.aulasari@gmail.com
}

\begin{abstract}
This perpose of this research was to know the isotherm, kinetics and thermodynamics adsorption of synthetic dye onto activated carcoal from palm oil shell. The synthetic dye were Reactive Red and Direct Blue. The model of isotherm were Langmuir and Freundlich, kinetics adsorption tested were Pseudo orde-1 and Pseudo orde-2, and also thermodynamics were free energy change $\left(\Delta \mathrm{G}^{0}\right)$, enthalpy change $\left(\Delta \mathrm{H}^{\circ}\right)$, and entropy change $\left(\Delta \mathrm{S}^{\circ}\right)$. The dominant isotherm adsorption was isotherm Freundlich, kinetic adsorption Pseudo 2 th order with the value $\left(\Delta \mathrm{S}^{\mathrm{o}}\right),\left(\Delta \mathrm{G}^{\mathrm{o}}\right)$ and $\left(\Delta \mathrm{H}^{\mathrm{o}}\right)$, Reactive Red were $0,0028 \mathrm{Kj} / \mathrm{mol} . \mathrm{K}$, $3,93 \mathrm{Kj} / \mathrm{mol}$, and $-36,12 \mathrm{Kj} / \mathrm{mol}$ respectively. Whereas in direct blue were $0,0034 \mathrm{Kj} / \mathrm{mol} . \mathrm{K},-1,67 \mathrm{Kj} / \mathrm{mol}$, and $-30,16 \mathrm{Kj} / \mathrm{mol}$ respectively.
\end{abstract}

Keywords : Adsorption, activated charcoal, palm oil shell, direct blue, reactive red.

\section{Abstrak}

Penelitian ini bertujuan untuk mengetahui isoterm, kinetika dan termodinamika adsorpsi zat warna sintetis oleh arang aktif tempurung kelapa sawit. Zat warna sintetis yang digunakan yaitu Reactive Red dan Direct Blue, Jenis isoterm yang diuji yaitu isoterm Langmuir dan Freundlich, kinetika adsorpsi yang diuji pseudo orde-1 dan pseudo orde-2 serta termodinamika yaitu energi bebas Gibbs $\left(\Delta \mathrm{G}^{\mathrm{o}}\right)$, entalpi $\left(\Delta \mathrm{H}^{\mathrm{o}}\right)$ dan entropi $\left(\Delta \mathrm{S}^{\mathrm{o}}\right)$. Pada penelitian ini Isoterm adsorpsi yang dominan adalah isoterm Freundlich, kinetika adsorpsi pseudo orde-2 dengan nilai $\left(\Delta \mathrm{S}^{\circ}\right),\left(\Delta \mathrm{G}^{\mathrm{o}}\right)$ dan $\left(\Delta \mathrm{H}^{\mathrm{o}}\right)$ pada Reactive Red berturut-turut adalah $0,0028 \mathrm{Kj} / \mathrm{mol} . \mathrm{K}$, $3,93 \mathrm{Kj} / \mathrm{mol}$, dan $-36,12 \mathrm{Kj} / \mathrm{mol}$, sedangkan pada Direct Blue berturut-turut adalah 0,0034 Kj/mol.K, $-1,67 \mathrm{Kj} / \mathrm{mol}$, dan $-30,16$ $\mathrm{Kj} / \mathrm{mol}$.

Kata kunci : Adsorpsi, arang aktif, tempurung kelapa sawit, direct blue, reactive red.

\section{PENDAHULUAN}

Batik besurek merupakan ciri khas dari kota Bengkulu. Dewasa ini , proses pewarnaan pada industri batik besurek zat warna alami telah digantikan dengan zat warna sintetis. Penggunaan zat warna sintetis ini menghasilkan limbah zat warna sintetik yang bersifat non-biodegradabel, karsinogenik dan dalam untuk jangka panjangnya dapat meng-akibatkan kerusakan hati, ginjal, anemia serta kelainan sel lainnya [1]. Direct dye dan Reactive dye tergolong pewarna sintetik yang memiliki struktur cincin benzena enam sampai sepuluh sehingga sangat stabil dan sulit untuk didegradasi secara biologi [2].

Berbagai metode telah dikembangkan dalam penanganan limbah zat warna di antaranya ozonisasi, oksidasi, koagulasi, dan adsorpsi [3], dimana salah satu cara pengolahan limbah yang tidak memerlukan biaya tinggi serta mudah untuk dilakukan adalah adsorpsi dengan menggunakan berbagai macam adsorben seperti kitosan, zeolit, silica gel, bentonit dan arang aktif [4], salah satunya adalah arang aktif dari tempurung kelapa sawit (AATKS) [5].
Pada suatu proses adsorpsi akan sangat dipenga ruhi oleh beberapa faktor antara lain berat adsorben, $\mathrm{pH}$ larutan, suhu, waktu kontak, dan ukuran molekul adsorben [6], karena itu perlu untuk diteliti lebih terperinci.

Tujuan penelitian ini ialah untuk menentukan mekanisme, besarnya kecepatan dan spontanitas reaksi adsorpsi yang terjadi ditentukan melalui pengukuran terhadap isoterm, kinetika dan termodinamika reaksi adsorpsi [7].

\section{METODE PENELITIAN}

Sampel tempurung kelapa sawit dicuci terlebih dahulu sampai bersih kemudian dijemur di bawah sinar matahari selama 4-8 hari sampai sampel kering. Proses karbonisasi dilakukan dengan cara memasukkan sampel limbah tempurung kelapa sawit ke dalam cawan porselen sesuai dengan kebutuhan penelitian, dipanaskan di dalam furnace, kemudian diatur suhunya maksimal 500 ${ }^{\circ} \mathrm{C}$, selama 3 jam dan dilakukan satu kali pembalikan arang supaya arang yang dihasilkan merata [8]. Pada proses aktivasi dilakukan dengan cara diayak arang dari hasil pembakaran menggunakan ayakan 100 mesh, 
kemudian direndam selama 24 jam dengan larutan $\mathrm{CaCl}_{2} 25 \%$ sebagai bahan aktivasi. Kemudian disaring dan dikeringkan menggunakan oven pada suhu $110^{\circ} \mathrm{C}$ selama 30 menit sehingga didapatkan arang aktif tempurung kelapa sawit (AATKS) [9].

Arang yang diperoleh kemudian dilakukan proses aktivasi yang bertujuan untuk meningkatkan daya serap dari arang tempurung kelapa sawit karena dapat memperbesar pori-pori adsorben yang dilakukan secara kimia menggunakan larutan $\mathrm{CaCl}_{2} 25 \%$, dengan cara merendam arang tempurung kelapa sawit yang telah dihaluskan ke dalam larutan $\mathrm{CaCl}_{2} 25 \%$ selama 24 jam, kemudian disaring dengan kertas saring dan dikeringkan di dalam oven pada $110{ }^{\circ} \mathrm{C}$ selama 30 menit. [10].

Penenentuan kapasitas adsorpsi maksimum AATKS ditentukan melalui kesetimbangan reaksi atau isoterm adsorpsi. Isoterm adsorpsi ditentukan dengan cara membuat variasi konsentrasi. Pada penelitian ini variasi konsentrasi yang digunakan adalah 25, 50, 75, $100,125,150,250,500$, dan 1000 ppm yang diperlakukan pada $\mathrm{pH}$ optimum dan waktu kontak optimum. Memipet masing-masing $10 \mathrm{~mL}$ larutan Reactive Red dan Direct Blue dengan variasi konsentrasi yaitu 25, 50, 75, 100, 125, 150, 250, 500, dan $1000 \mathrm{ppm}$ yang telah diatur pada $\mathrm{pH}$ asam lalu ditambahkan arang aktif $150 \mathrm{mg}$ dan diaduk menggunakan shaker dengan kecepatan 150 rpm pada waktu kontak optimum. Kemudian disaring dan diukur absorbansinya dengan spektrofotometer UV-Vis. Untuk menentukan pola adsorpsi larutan zat warna Reactive Red dan Direct Blue pada permukaan AATKS digunakan dua model isoterm adsorpsi

Untuk menentukan termodinamika proses adsorpsi dilakukan dengan cara mempipet masing masing $10 \mathrm{~mL}$ larutan zat warna Reactive Red dan Direct blue. 100 ppm, larutan diatur pada $\mathrm{pH}$ asam. Ditambahkan arang aktif $150 \mathrm{mg}$ dan diaduk menggunakan shaker dengan kecepatan 150 rpm dengan waktu kontak optimum dan masing masing larutan dilakukan dengan variasi suhu $30{ }^{\circ} \mathrm{C}, 40{ }^{\circ} \mathrm{C}$ dan $50{ }^{\circ} \mathrm{C}$.. Kemudian disaring dan diukur absorbansinya dengan spektrofotometer UV - Vis.

Kinetika adsorpsi menunjukkan tingkat kecepatan penjerapan adsorben terhadap adsorbatnya. Pada penentuan model kinetika adsorpsi terhadap zat warna oleh AATKS, dilakukan dengan pengukuran 2 konsentrasi larutan Reactive Red dan Direct Blue (50 ppm dan 100 ppm) setiap selang waktu kontak yaitu 5, 10, 20, 30, 40, 60, 90, 120 menit dan 24 jam hingga dicapai kesetimbangan pada suhu kamar. Dalam kinetika adsorpsi terdapat dua model kinetika yang digunakan yaitu model pseudo orde-1 dan pseudo orde-2. Memipet masing-masing $10 \mathrm{~mL}$ larutan $50 \mathrm{ppm}$ dan $100 \mathrm{ppm}$ dari zat warna, diatur pada $\mathrm{pH}$ asam dan dimasukkan ke dalam botol vial, ditambahkan $40 \mathrm{mg}$ arang aktif dan diaduk menggunakan shaker dengan kecepatan $150 \mathrm{rpm}$ pada masing masing waktu kontak tersebut. Kemudian disaring dan diukur absorbansinya dengan spektrofotometer UV-vis.

\section{HASIL DAN PEMBAHASAN}

Pada proses pembuatan arang aktif dalam penelitian ini sampel tempurung kelapa sawit yang telah dikeringkan dilakukan proses karbonisasi menggunakan furnace dengan suhu $500{ }^{\circ} \mathrm{C}$ selama $3 \mathrm{jam}$.

Hasil penentuan terhadap isoterm adsorpsi menghasilkan kurva adsorpsi berupa isoterm Freundlich untuk adsorben AATKS dapat dilihat pada Gambar 1 dan 2.

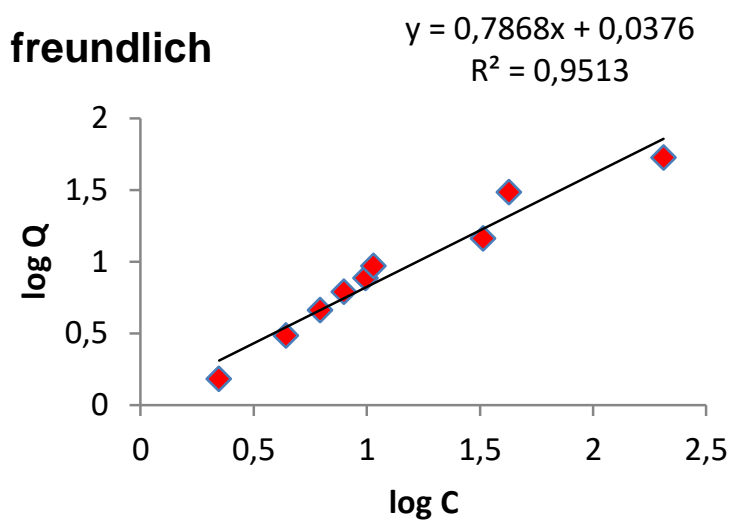

Gambar 1. Isoterm Freundlich larutan zat warna Reactive Red menggunakan AATKS

Berdasarkan Gambar 1 dapat dilihat nilai koefisien determinasi $\left(\mathrm{R}^{2}\right)$ penyerapan zat warna Reactive Red oleh AATKS sebesar 0,951, yang memperlihatkan bahwa adsorpsi zat warna Reactive red cenderung mengikuti persamaan isoterm Freundlich, yang berarti adsorpsi berlangsung secara fisisorpsi multilayer [11].

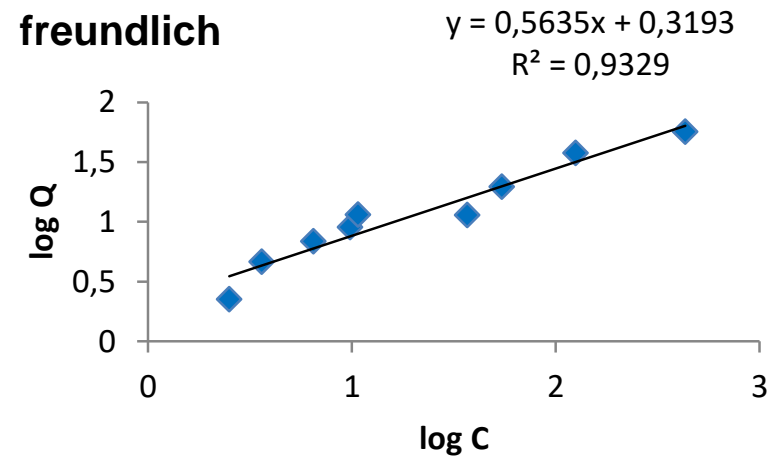

Gambar 2.Isoterm Freundlich larutan zat warna Direct Blue menggunakan AATKS 
Pada Gambar 2 dapat dilihat penyerapan AATKS terhadap Direct Blue diperoleh dapat dilihat nilai koefisien determinasi $\left(\mathrm{R}^{2}\right)$ penyerapan zat warna Direct Blue oleh AATKS, adalah sebesar 0,932, yang memperlihatkan bahwa adsorpsi zat warna Direct Blue cenderung mengikuti persamaan isoterm Freundlic, yang berarti adsorpsi berlangsung secara fisisorpsi multilayer. Dari Gambar 1 dan 2 dapat disimpulkan bahwa isoterm adsorpsi untuk kedua zat warna tersebut pada penelitian ini adalah isoterm Freundlich dengan kapasitas adsorpsi larutan zat warna Reactive Red 53,2 $\mathrm{mg} / \mathrm{g}$ dan larutan zat warna Direct Blue $56,7 \mathrm{mg} / \mathrm{g}$.

Dari persamaan garis linear yang didapat melalui pembuatan grafik isoterm Freundlich dapat digunakan untuk menentukan parameter Freundlich, $\mathrm{K}_{\mathrm{F}}, \mathrm{n}$ dan $\mathrm{Q}_{\max }(\mathrm{mg} / \mathrm{g})$ arang aktif masing-masing zat warna yang terlihat pada Tabel 1, sesuai dengan persamaan Freundlich :

$$
\log q_{e}=\log K_{F}+\frac{1}{n} \log C_{e}
$$

Tabel 1. Parameter Model Isoterm Freundlich pada Penyerapan Zat Warna

\begin{tabular}{cccc}
\hline \multirow{2}{*}{$\begin{array}{c}\text { Arang } \\
\text { Aktif }\end{array}$} & Parameter & \multicolumn{2}{c}{ Zat Warna } \\
\cline { 3 - 4 } & Freundlich & Reac.Red & Dir.Blue \\
\hline \multirow{4}{*}{ AATKS } & $\mathrm{K}_{\mathrm{F}}$ & 1,09 & 2,08 \\
& $\mathrm{q}_{\max }$ (Perc.) & 53,2 & 56,7 \\
& $\mathrm{~N}$ & 1,27 & 1,78 \\
& $\mathrm{R}^{2}$ & 0,951 & 0,932 \\
& $\mathrm{q}_{\mathrm{e}}$ (Persm.) & 6,63 & 7,64
\end{tabular}

Keterangan: $\mathrm{K}_{\mathrm{F}}=$ parameter Freundlich, $\mathrm{q}_{\mathrm{e}}=$ kapasitas adsorpsi (mg/g), $\mathrm{q}_{\max }=$ kapasitas adsorpsi maksimum $(\mathrm{mg} / \mathrm{g}), \quad \mathrm{n}=$ Konstanta Empiris dan $\mathrm{R}^{2}=$ koefisien determinasi

Nilai $\mathrm{K}_{\mathrm{F}}$ menunjukkan kapasitas adsorpsi suatu adsorben. Hal Ini menandakan bahwa proses adsorpsi yang terjadi adalah secara fisisorpsi multilayer. Pendekatan Freundlich mengasumsikan bahwa permukaan adsorben bersifat heterogen, adsorpsi membentuk banyak lapisan. Hal ini memungkinkan adsorbat leluasa bergerak hingga berlangsung proses adsorpsi yang terjadi pada banyak lapisan adsorpsi yang berlangsung secara fisik (fisisorpsi) [11].

Hasil pengukuran dan perhitungan termodinamika adsorpsi, dibuat grafik hubungan $1 / \mathrm{T}$ terhadap $\ln \mathrm{Kd}$ pada larutan zat warna Reactive Red dan Direct Blue oleh AATKS seperti terlihat pada Gambar 3. Berdasarkan gambar 3 akan diperoleh parameter termodinamika adsorpsi yaitu nilai entalpi $\left(\Delta \mathrm{H}^{\circ}\right)$, entropi $\left(\Delta \mathrm{S}^{\circ}\right)$ dan energi bebas Gibbs $\left(\Delta \mathrm{G}^{\circ}\right)$.

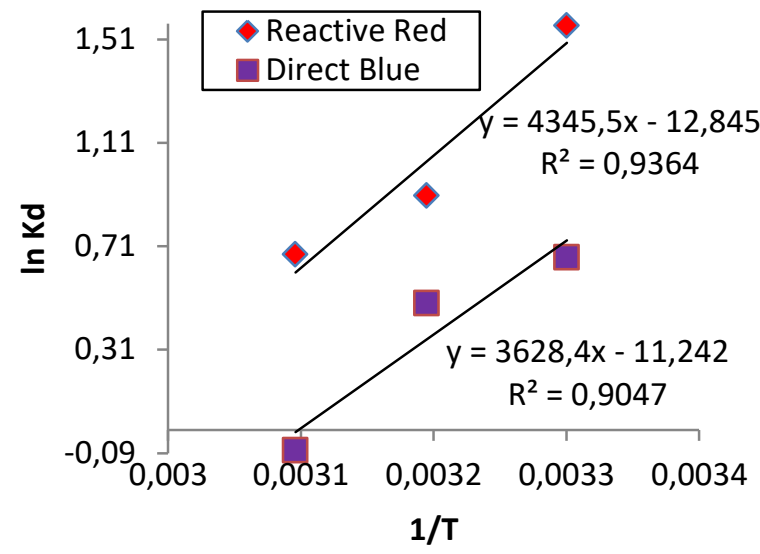

Gambar 3 Kurva Hubungan Ln Kd dan 1/T untuk zat warna Reactive Red dan Direct Blue oleh AATKS

Nilai parameter termodinamika seperti yang terlihat pada Tabel 2 dan 3 dengan menggunakan persamaan berikut :

$$
\begin{aligned}
& \Delta \mathrm{G}^{\mathrm{o}}=-\mathrm{RT} \ln \mathrm{K}_{\mathrm{d}} \\
& \mathrm{Ln} \mathrm{K}_{\mathrm{d}}=\left(-\frac{\Delta H^{o}}{R}\right) \frac{1}{T}+\frac{\Delta S^{o}}{R} \\
& \Delta \mathrm{S}^{\mathrm{o}}=\frac{q_{r e v}}{T}
\end{aligned}
$$

Tabel 2. Data Hasil Termodinamika Reactive Red oleh AATKS

\begin{tabular}{cccc}
\hline \multirow{2}{*}{$\begin{array}{c}\text { Temperatur } \\
(\mathrm{K})\end{array}$} & \multicolumn{3}{c}{ Parameter Termodinamika } \\
\cline { 2 - 4 } & $\begin{array}{c}\Delta \mathrm{G}^{\mathrm{o}} \\
(\mathrm{Kj} / \mathrm{mol})\end{array}$ & $\begin{array}{c}\Delta \mathrm{H}^{\mathrm{o}} \\
(\mathrm{Kj} / \mathrm{mol})\end{array}$ & $\begin{array}{c}\Delta \mathrm{S}^{\mathrm{o}} \\
(\mathrm{Kj} / \mathrm{mol} . \mathrm{K})\end{array}$ \\
\hline 303 & $-3,93$ & & \\
313 & $-2,35$ & $-36,12$ & 0,0028 \\
323 & $-1,82$ & & \\
\hline
\end{tabular}

Tabel 3. Data Hasil Termodinamika Direct Blue oleh AATKS

\begin{tabular}{cccc}
\hline \multirow{2}{*}{$\begin{array}{c}\text { Temperatur } \\
(\mathrm{K})\end{array}$} & \multicolumn{3}{c}{ Parameter Termodinamika } \\
\cline { 2 - 4 } & $\begin{array}{c}\Delta \mathrm{G}^{\mathrm{o}} \\
(\mathrm{Kj} / \mathrm{mol})\end{array}$ & $\begin{array}{c}\Delta \mathrm{H}^{\mathrm{o}} \\
(\mathrm{Kj} / \mathrm{mol})\end{array}$ & $\begin{array}{c}\Delta \mathrm{S}^{\mathrm{o}} \\
(\mathrm{Kj} / \mathrm{mol} . \mathrm{K})\end{array}$ \\
\hline 303 & $-1,68$ & & \\
313 & $-1,27$ & $-30,16$ & 0,0034 \\
323 & 0,22 & & \\
\hline
\end{tabular}


Berdasarkan parameter termodinamika adsorpsi untuk zat warna Reactive Red didapatkan besarnya $\Delta \mathrm{G}^{\mathrm{o}}=$ bernilai negatif $, \Delta \mathrm{Ho}=-36,12 \mathrm{Kj} / \mathrm{mol}$ dan $\Delta \mathrm{S}^{\mathrm{o}}$ $=0,0028 \mathrm{Kj} / \mathrm{mol}$.K. Sedangkan pada zat warna Direct Blue untuk $\Delta \mathrm{G}^{\circ}=$ bernilai negatif $, \Delta \mathrm{H}^{\mathrm{o}}=-30,16$ $\mathrm{Kj} / \mathrm{mol}$ dan $\Delta \mathrm{S}^{\mathrm{o}}=0,0034 \mathrm{Kj} / \mathrm{mol} . \mathrm{K}$. Hal ini menunjukkan bahwa proses adsorpsi kedua zat warna berlangsung berlangsung secara spontan pada reaksi eksoterm dengan gangguan terhadap sistem adalah kecil.[12]

Kurva reaksi adsorpsi pseudo orde- 2 untuk kedua zat warna yang terlihat pada Gambar 4 .

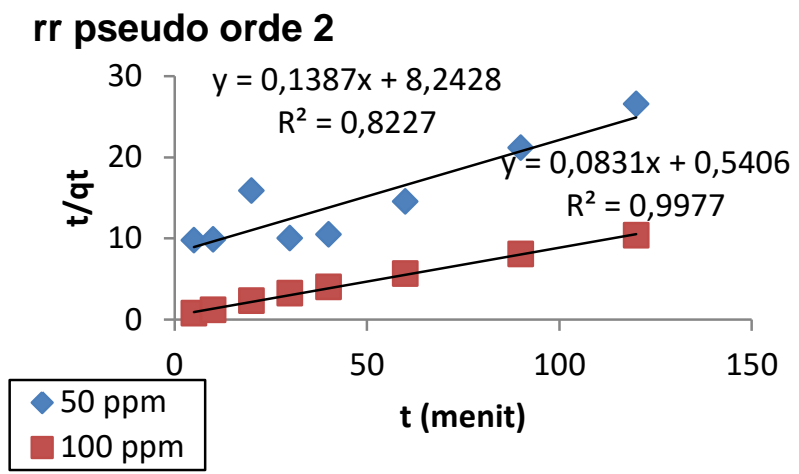

Gambar 4. Kurva kinetika adsorpsi pseudo orde-2 dari Reactive Red

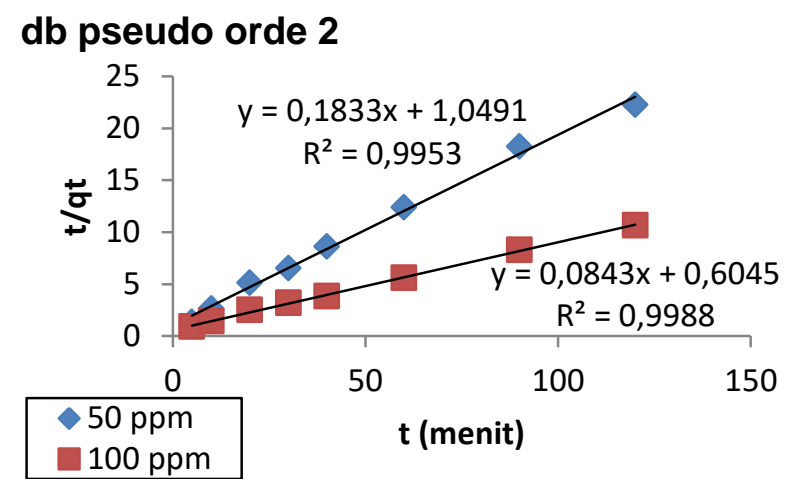

Gambar 5. Kurva kinetika adsorpsi pseudo orde-2 dari Direct Blue

Berdasarkan Gambar 4 zat warna Reactive Red pada pseudo orde-2 dilihat dari nilai koefisien determinasinya $\left(\mathrm{R}^{2}\right)=0,822$ pada konsentrasi $50 \mathrm{ppm}$ dan $R^{2}=0,997$ pada konsentrasi $100 \mathrm{ppm}$, dan untuk zat warna Direct Blue $\mathrm{R}^{2}$ berturut-turut adalah 0,995 (50 ppm) dan 0,998 (100 ppm).

Oleh karena itu dapat disimpulkan bahwa untuk zat warna Reactive Red dan Direct Blue kinetika adsorpsi keduanya mengikuti orde dua, yang mengasumsikan bahwa kapasitas menyerap proporsional terhadap jumlah permukaan karbon aktif dan juga tergantung dari kemampuan masing-masing arang aktif dalam mengadsorpi zat warna [13].
Penentuan kinetika adsorpsi orde 2 didapat dengan menggunakan persamaan berikut :

$$
\frac{t}{q_{t}}=\frac{1}{k_{2} q_{e}^{2}}+\frac{1}{q_{t}} t
$$

Hasil perhitungannya dapat dilihat pada Tabel 4 di bawah ini :

Tabel 4. Parameter larutan zat warna Reactive Red dan Direct Blue pada orde 2

\begin{tabular}{ccccc}
\hline \multirow{2}{*}{ C Awal } & \multicolumn{2}{c}{$\mathrm{q}_{\mathrm{e}}$} & \multicolumn{2}{c}{$\mathrm{K}_{2}$} \\
\cline { 2 - 5 } & $\mathrm{RR}$ & $\mathrm{DB}$ & $\mathrm{RR}$ & $\mathrm{DB}$ \\
\hline $50 \mathrm{ppm}$ & 7,25 & 5,46 & 0,0023 & 0,0320 \\
$100 \mathrm{ppm}$ & 12,05 & 11,90 & 0,0127 & 0,0117 \\
\hline Keterangan : $\mathrm{q}_{\mathrm{e}}:$ kapasitas adsorpsi (mg/g), \\
$\mathrm{K}_{2}:$ konstanta laju,
\end{tabular}

Berdasarkan Tabel 4 kapasitas adsorpsi yang di-peroleh lebih besar pada konsentrasi 100 ppm yaitu $12,05 \mathrm{mg} / \mathrm{g}$ untuk Reactive Red dan 11,90 mg/g untuk Direct Blue diandingkan pada konsentrasi $50 \mathrm{ppm}$. Hal ini karena semakin besar konsentrasi larutan zat warna maka kapasitas adsorpsi akan semakin besar karena zat warna akan lebih banyak terserap. Jadi dapat disimpulkan bahwa model kinetika adsorpsi AATKS pada larutan zat warna Reactive Red dan Direct Blue mengikuti model kinetika adsorpsi Pseudo Orde 2

\section{KESIMPULAN}

Adsorpsi larutan zat warna Direct Blue dan Reactive Red oleh AATKS mengikuti isoterm Freundlich dan model kinetika adsorpsi Pseudo Orde-2 serta nilai $\left(\Delta \mathrm{G}^{\circ}\right),\left(\Delta \mathrm{H}^{\circ}\right)$ dan $\left(\Delta \mathrm{S}^{\circ}\right)$ pada Reactive Red berturut - turut adalah $-3,93 \mathrm{Kj} / \mathrm{mol},-36,12 \mathrm{Kj} / \mathrm{mol}$ dan $0,0028 \mathrm{Kj} / \mathrm{mol} . \mathrm{K}$ sedangkan pada Direct Blue berturut turut adalah $-1,67 \mathrm{Kj} / \mathrm{mol}, \quad-30,16 \mathrm{Kj} / \mathrm{mol}$ dan $0,0034 \mathrm{Kj} / \mathrm{mol} . \mathrm{K}$.

\section{SARAN}

Untuk mendapatkan data hasil adsorpsi AATKS terhadap zat warna sintetis yang lebih bermanfaat maka perlu penambahan jumlah perlakuan dan tingkat pengulangan terhadap masing masing variabel yang diukur dan juga pada zat warna sintetis lainnya.

\section{DAFTAR PUSTAKA}

[1] Manurung, R., Hasibuan, R., dan Irvan. 2004. Perombakan Zat Warna Azo Reaktif Secara Anaerob-Aerob. Skripsi : Respository Universitas Sumatera Utara. 
[2] Firdaus, M.L., Krisnanto, N., Alwi, W., Muhammad, R., dan Serunting, M.A. 2017. Adsorption of Textile Dye by Activated Carbon Made from Rice Straw and Palm Oil Midrib. Aceh International Journal of Science and Technology, 7(1): 1-7.

[3] Muna, N. 2014. Adsorpsi Zat Warna Malachite Green (MG) Oleh Komposit Kitosan-Bentonit. SKRIPSI: Respository Universitas Islam Negeri Sunan Kalijaga.

[4] Panda, R.D. 2012. Modifikasi Bentonit Terpilar Al Dengan Kitosan Untuk Adsorpsi Ion Logam Berat. SKRIPSI: Respository Universitas Indonesia.

[5] Pambayun, G.S., Remigius, Y.E., Yulianto, Rachimoellah, M., Putri, E.M.M. 2013. Pembuatan Karbon Aktif Dari Arang Tempurung Kelapa Dengan Aktivator $\mathrm{ZnCl}_{2}$ dan $\mathrm{Na}_{2} \mathrm{CO}_{3} \mathrm{Se}$ bagai Adsorben Untuk Mengurangi Kadar Fenol Dalam Air Limbah. SKRIPSI: Respository Institut Teknologi Sepuluh November.

[6] Wiyarsi dan Erfan. 2009. Pengaruh Konsentrasi Kitosan Dari Cangkang Udang Terhadap Efisiensi Penjerapan Logam. SKRIPSI: Respository Universitas Sebelas Maret.

[7] Achmad, A., Kassim, J., Suan, T.K., Amat, R.C., dan Seey, T.L. 2012. Equilibrium, Kinetic and Thermodynamic Studies on the Adsorption of Direct Dye onto a Novel Green Adsorbent Deve-loped from Uncaria Gambir Extract. Journal of Physical Science. 23(1): 1-13.
[8] Kurniarti, E. 2008. Pemanfaatan Cangkang Kelapa Sawit Sebagai Arang Aktif. Jurnal teknik kimia UNP. 8(2): 1-8.

[9] Jamilatun, S dan Setyawan. 2014. Pembuatan Arang Aktif dari Tempurung Kelapa dan Aplika-sinya untuk Penjernihan Asap Cair. Jurnal Spektrum Industri Teknik Kimia UAD Yogyakarta. 12(1): 1-6.

[10] Fitri, M. 2013. Pembuatan Arang Aktif Dari Pelepah Sawit Menggunakan Aktivator $\mathrm{NaOH}$ dan $\mathrm{ZnCl}_{2}$.SKRIPSI: Respository Universitas Negeri Sultan Syarif Kasim Riau.

[11] Atkins, P.W. 1999. Kimia Fisika Jilid 1.Jakarta: Erlangga.

[12] Lyubchik, S. 2000. Comparison Of The Thermodynamic Parameters Estimation For The Adsorption Process Of The Metals From Liquid Phase On Activated Carbon.Portugal: Intech, ISBN: 978-953-307-563-1.

[13] Firdaus, M.L. Alwi,W, Trinoveldi,T, Rahayu,I, Rahmidar,L, Warsito,K . 2014. Determination of Chromium and Iron Using Digital Imagebased Colorimetry. Procedia Environmental Sciences, 20:304.

Penulisan Sitasi Artikel ini ialah :

Sari, R.A, Firdaus,M.L, Elvia，R, 2017, Penentuan Kesetimbangan, Termodinamika dan Kinetika Adsorpsi Arang Aktif Tempurung Kelapa Sawit Pada zat Warna Ractive Red dan Direct Blue, Alotrop,1(1):10-14. 